\title{
Research of the Friction Clutch Automatic Control Performance at the Stand
}

\author{
Aleksandr Blokhin, Lev Barakhtanov, Alla Koshurina, Aleksandr Taratorkin and Pavel Lubichev \\ Transport systems institute, Nizhny Novgorod State Technical University named after R.E. Alekseev (NNSTU), Russian \\ Federation
}

\begin{abstract}
The paper describes the research conducted at the NNSTU named after R. E. Alekseev on development and creation of multi-clutch manual transmission with automatic control and pneumatic drive. We propose the general scheme of the transmission and clutch control, design modelof the clutch control mechanism, general equations that allow us to choose necessary drive parameters, and the data of the experimental studies, obtained on the specialized stand.
\end{abstract}

Keywords-friction clutch; automatic mechanical transmission; electro-drive; automatic control

\section{INTRODUCTION}

With heavy city traffic or when driving on broken terrain,we must shift gears every 15-25 seconds. As a result, in vehicles equipped with multi-stage mechanical transmission, every $100 \mathrm{~km}$ of track may account for 1000-1500 shutdowns of the friction clutch $[3,7]$. This leads to the driver's fatigue and deterioration of his well-being, but also to an increase in errors while driving. This is especially true in the control of heavy trucks, trains and buses. Providing of safety and high performance of heavy vehicles in these conditions may be effected by automation of the control of mechanical speed transmission, especially of a gearbox and a clutch. Therefore, nowadays the automatic control of transmission associated with the desire to facilitate and simplify the process of driving is developing faster and faster. Forroad vehicles the systems of automatic and semi-automatic (command) transmission and clutch control are being developed (robotizedtransmission). Now electro-pneumatic drives of transmission control have increasing development in the multi-stage mechanical transmissions. This is due tothe fact thattrucks and buses have compressors required for the control of the brakes, doors and so on. The aim of this work is the development of new technical solutions for creation of mechanisms of the friction clutch automatic control forpotential heavy-duty trucks and buses.

\section{ANALYSIS OF THE REQUIREMENTS FOR THE CLUTCH CONTROL MECHANISM}

The friction clutch is a major element of the mechanical transmission connecting it to the engine. Therefore, there are high requirements to this unit [1-3]. Let's consider the most important basic requirements. The design of the clutch control mechanism must provide:

1) Rapid (maximum 0.25 seconds) release of the clutch when shifting and fast but soft start after the shifting;
2) The possibility of continuous operation with slipping, i.e.kinematic mismatch between driving and driven elements, which must be at the beginning of the movement for smooth starting and in maneuvering for fine adjustment of the speed of the vehicle;

3) Release (turning off) at decreasingof the angular rotational speed of the crankshaft of the engine to the idle speed so that in case of braking the vehicle to a stop the possibility of stopping the engine would be excluded;

4) The transfer of torque in the opposite direction (from the drive wheels to the engine) with the engine running or not. It is necessary for engine braking when driving and in the parking lot, as well as for starting the engine throughtowing of the vehicle;

5) Prevention of the transmission parts from being overloadedby the dynamic torque.

6) The clutch control mechanism must be designed as a separate unit and act upon the clutch release fork.

7) The clutch control mechanism should consist of multiple execution units performing control and power functions.

8) The design of the mechanism should exclude the possibility of the air leakage from the cavities of the accelerator mechanism and the pneumatic cylinder clutch.

9) Pneumatic air supply of the control mechanism must be carried out from the board pneumatic system of the vehicle with a maximum pressure of $7.2 \mathrm{~kg} / \mathrm{cm}^{2}$.

10) The solenoidsmust be built into the control mechanism that will prevent the airway and thereby improve the performance and reliability of the mechanism.

\section{THE OBJECT OF STUDY}

One of the most common models of the frictional clutch used on heavy trucks and buses is ZF Sachs MFZ 430, the main characteristics of which are presented in Table $1[6,7,9]$.

\section{THE METHOD OF THEORETICAL RESEARCH}

To control the friction clutch ZF SACHS MFZ 430 as part of the mechanical transmission mechanism the design model shown in Figure 1 was chosen. 
TABLE I. MAIN CHARACTERISTICSOF THE CLUTCH ZF SACHS MFZ 430

\begin{tabular}{|c|c|}
\hline The transmissible torque, N.m & 1600 \\
\hline The number of working surfaces & 2 \\
\hline \multicolumn{2}{|c|}{ The friction linings diameter, $\mathrm{mm}$ : } \\
\hline outside & 430 \\
\hline inside & 240 \\
\hline \multicolumn{2}{|l|}{ Thickness, mm: } \\
\hline drivenbrakedisk & 10 \\
\hline lining & 3,6 \\
\hline \multicolumn{2}{|l|}{ Compressionspring: } \\
\hline type & central, diaphragm \\
\hline quantity & 1 \\
\hline \multicolumn{2}{|c|}{ Diaphragm effort at coupling, kN(kilogram-force) } \\
\hline Power on & $28(2800)$ \\
\hline Power off & $25(2500)$ \\
\hline \multicolumn{2}{|c|}{ Pressure diaphragm spring parameters: } \\
\hline Thickness, mm: & 5,1 \\
\hline \multicolumn{2}{|l|}{ Diameter, mm: } \\
\hline outside & 393 \\
\hline contact with the bearing & 120 \\
\hline the number of petals & 24 \\
\hline $\begin{array}{l}\text { The force on the release clutch, } \mathrm{kN} \\
\text { (kilogram-force) }\end{array}$ & $60(600)$ \\
\hline The gear ratio of the spring & 4,84 \\
\hline Type of damper & spring-friction \\
\hline $\begin{array}{l}\text { The maximum angle of the damper rotation, } \\
\text { degrees }\end{array}$ & 13 \\
\hline \multicolumn{2}{|c|}{ The hub splines of the driven disk } \\
\hline Type & straight-sided \\
\hline quantity & 10 \\
\hline \multicolumn{2}{|l|}{ Diameter, mm: } \\
\hline outside & 50,8 \\
\hline inside & 44 \\
\hline groove width & 7,8 \\
\hline \multicolumn{2}{|c|}{ The release clutch stroke, $\mathrm{mm}$ : } \\
\hline Free-wheel cluch & - \\
\hline Operatingstroke & 12 \\
\hline Type of release bearing: & $\begin{array}{l}\text { ball, singlerow, } \\
\text { closed }\end{array}$ \\
\hline \multicolumn{2}{|l|}{ Weight, kg: } \\
\hline $\begin{array}{l}\text { the clutch assembly (without a flywheel and } \\
\text { a drive mechanism), kg }\end{array}$ & 36 \\
\hline Driven disk & 6,5 \\
\hline
\end{tabular}

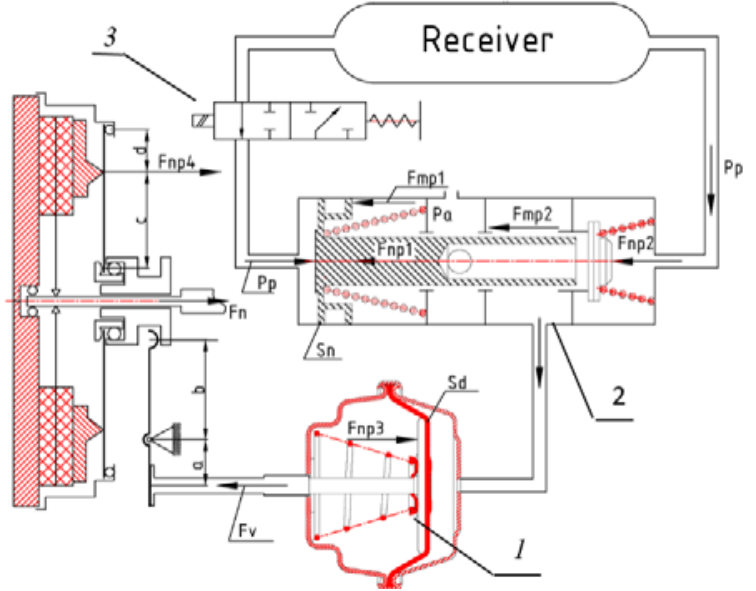

FIGURE I. THE DESIGN MODEL OF THE CLUTCH CONTROL MECHANISM.

As we can see from the diagram (Figure 1), the clutch control mechanism consists of two major parts: force chamber (Pos. 1) and the acceleration mechanism (pos. 2). When voltage is applied to the solenoid valve (Pos. 3) the air from the receiver enters the cavity behind the piston of the acceleration mechanism. As a result, this leads to the opening of the injection valve, through which the pressure of the compressed air is transferred to the power chamber, causes displacement of the piston rod of the force chamber, of the clutch plug and of the other components and releases the clutch. In order to turn the clutch on, the voltage from the solenoid valve must be removed(Pos. 3). In this case, under the action of the return spring mechanisms the details of the clutch mechanism return to their original position and the pressure in the power chamber reduces to the atmospheric value.

The main parameters of the clutch control mechanism: the cross section of the feeding channels, diameters of the active elements, rigidity of the system. The permissible values of friction components were determined on the basis of the solution of the differential equation:

$$
m \cdot \frac{d_{2} x}{d t_{2}}+c \cdot x=a \cdot t-b
$$

where $x$ is replacement of the rod of the given unit (the rod of the power cylinder or piston of the acceleration mechanism).

In equation (1) the coefficient $a$ is connected with changes in the system pressure, which is determined by the expression:

$$
\frac{d p}{d t}=\frac{R T}{V} \mu F \sqrt{\frac{2 g}{R T} p_{p}^{2} \frac{k}{k+1}\left(\frac{2}{k+1}\right)^{\frac{2}{k-1}}}
$$




$$
\frac{d p}{d t}=\frac{R T}{V} \mu F p_{p} \sqrt{\frac{2 g k}{R T(k-1)}\left[\left(\frac{p}{p_{p}}\right)^{\frac{2}{k}}-\left(\frac{p}{p_{p}}\right)^{\frac{k+1}{k}}\right]}
$$

where $p_{p}-$ is the pressure in the receiver, from which the outflow of the air takes place; $p$ - is the current pressure in the power cylinder, $\mathrm{H} / \mathrm{M}^{2} ; V-$ is the volume of the cylinder, where the flow takes place, $\mathrm{M}^{3} ; T-$ is the absolute temperature of the air, ${ }^{\circ} \mathrm{K} ; R$ - the gas constant, $\frac{N \cdot m}{N \cdot{ }^{\circ} \mathrm{K}}$, $\mathrm{R}=29.27 ; k$ - the ratio of the adiabat for the air , $\mathrm{k}=1.41, \mathrm{~g}-$ acceleration of gravity, $\mathrm{m} / \mathrm{s}^{2} ; \mu$ - the flow coefficient $; F$ Cross-section of the orifice through which the outflow of air takes place, $\mathrm{m}^{2}$.

Expression (2) is used for the critical zone of the outflow of air, and (3) - for the subcritical zone.

Using equations (1) - (3) we obtained regression dependence (4) of the time of replacement of the clutch control accelerator mechanism from the main parameters of the pneumatic drive:

$$
t=0,7897+746,93 \cdot F_{1}-3,179 \cdot C_{1}-92,01 \cdot S_{1}
$$

Where $F_{l}$ is- the cross sectional area of the solenoid valve; $C_{l}$ is the total rigidity of the return spring; $S_{I}$ is the diameter of the piston of the acceleration mechanism

On the basis of relation (4) we identified rational values of the solenoid valve passage area, the total rigidity of return springs and the diameter of the acceleration mechanism piston. With their help we developed the engineering documentation for the clutch control mechanism.

\section{IMPLEMENTATION OF THE OBJECT OF STUDY}

In Figure 2, the appearance of the clutch control mechanism, as in Figure 3 - kind of mechanism at the multistage transmission.

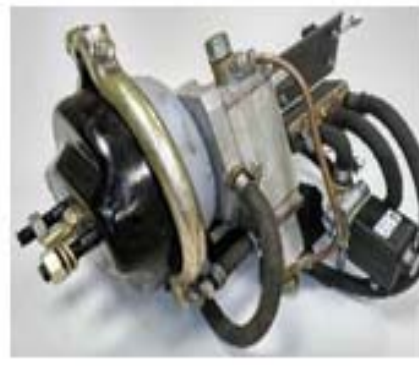

a)

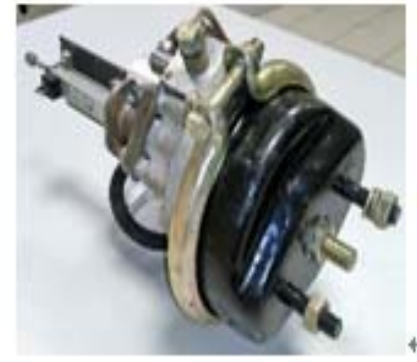

b)
FIGURE II. THE CLUTCH CONTROL MECHANISM

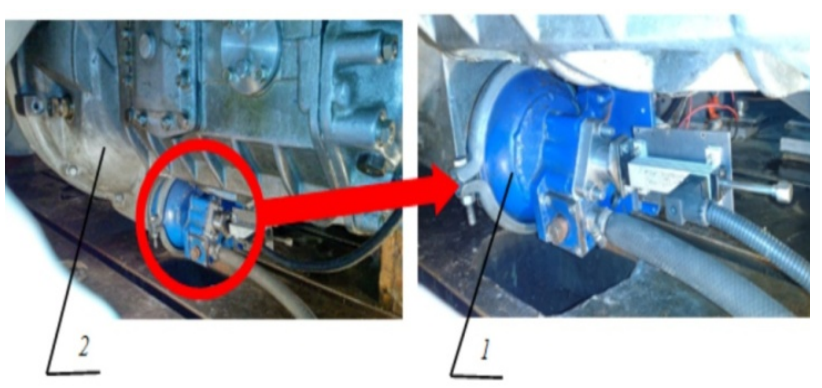

1 - the designed clutch control mechanism; 2 - multistage transmission.

FIGURE III. TYPE OF THE CLUTCH CONTROL MECHANISM INSTALLED ON THE TRANSMISSION

Figure 4 shows a diagram of the connection of the friction clutch Sachs MFZ-430 with the developed automatic clutch control mechanism.

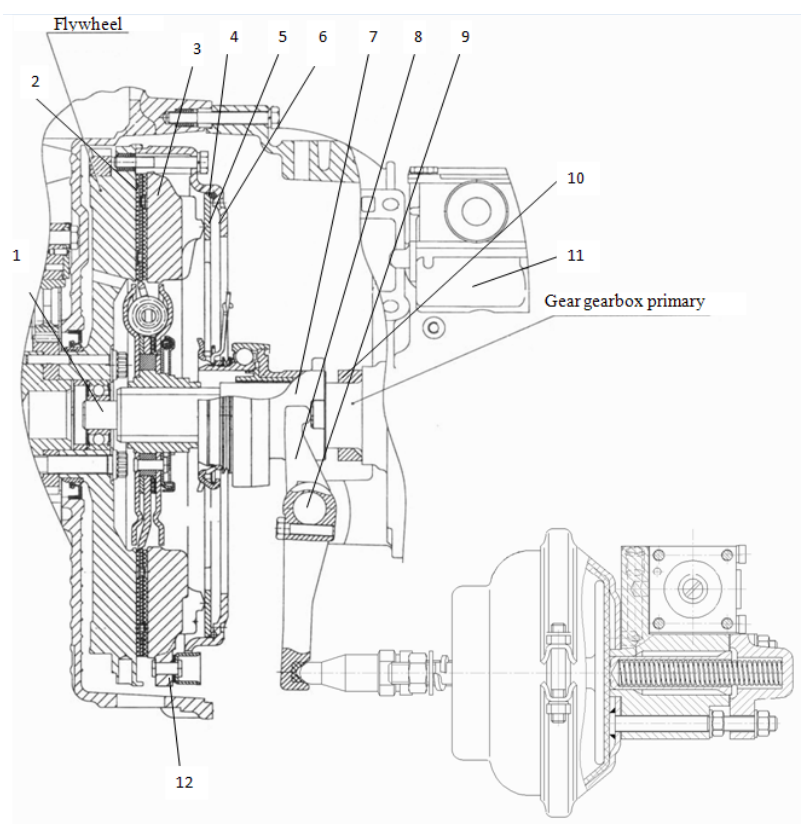

1 - the drive shaft; 2 - the driven plate; 3 - the pressure plate; 4 - the thrust ring; 5 - the diaphragm; 6 - the clutch cover; 7 -the clutch release sleeve; 8 - the clutch fork; 9 -the clutch operating shaft; 10 - the restrictive ring; 11 - the gearbox; 12 - the connecting plate

\section{FIGURE IV. THE DIAGRAM OF CONNECTION OF THE CLUTCH OF THE SACHS MFZ-430 MODEL WITH THE AUTOMATIC CLUTCH CONTROL MECHANISM}

\section{THE METHOD AND RESULTS OF EXPERIMENTAL STUDIES}

The NNSTU named after R. E. Alekseev (Nizhny Novgorod, Russia) carried out experimental research on a specialized stand, RF patents №154871, №154102 (Figure 4) for testing of transmissions with command control and automatic control $[4,5,8]$. The stand allows us to carry out the study of efficiency of the units of mechanical transmissions (the clutch, the divider, the main gear, the splitter, determining the efficiency of the units, the study of the synchronization process, etc.) and mechatronic control systems for automatic orsemi-automatic modes. At this stand we worked out the clutch control algorithms for multi-stage mechanical gearboxes. 


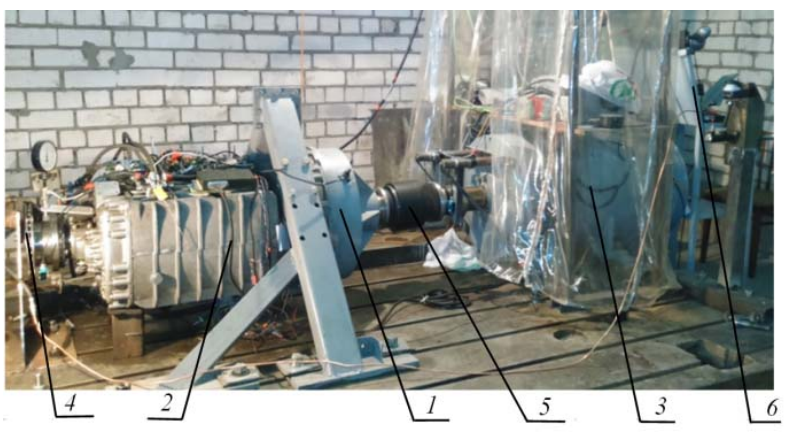

1 - the researchedclutch control mechanism, 2 - the multi-stage transmission; 3 - the drive motor 4 -the disc friction brake with a hydraulic drive; 5 - the driveline; 6 - remote control stand.

FIGURE V. THE STAND FOR THE STUDY OF THE EFFICIENCY OF THE MECHANISM OF THE AUTOMATIC CLUTCH CONTROL

In the process of experimental research is necessary to establish the actual dependence of the stock clutch fork from the position of the gas pedal (not shown in Figure 5) located on the control board of the stand 6 and the frequency of rotation of the drive motor 3 with different loads on the output shaft. The load on the output shaft is created by a hydraulic disc brake 4, the pressure in the drive is controlled by a sensor. The discrepancy between the obtained dependence and theoretical curve, embedded into the the algorithm of the microprocessor clutch and gearbox control system must be maximum $5 \%$.

In the process of experimental research made by the measuring tools we recorded values of the positions of the fork clutch rod, the pressure in the power chamber, the pressure in the acceleration mechanism, theposition of the gas pedal, the torque and rotation speed on the shaft of the drive motor. The analysis of these parameters allows us to estimate the performance of the automatic clutch control mechanism in the vehicle starting simulation mode.

Figures 6-7 shows the experimentally obtained characteristics of the above parameters.

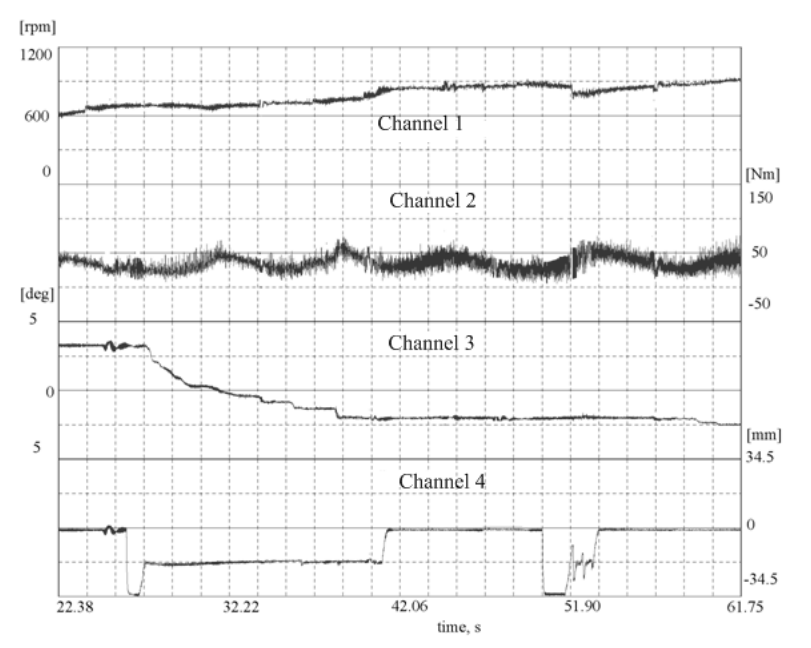
channel 1 - the engine shaft speed; channel 2 - the engine torque; channel 3 -position of thegas pedal;
channel 4 - position of the clutch fork rod

FIGURE VI. EXPERIMENTAL DATA OF THE REPOSITIONING FORK CLUTCH ROD IN THE VEHICLE STARTING SIMULATION MODE:

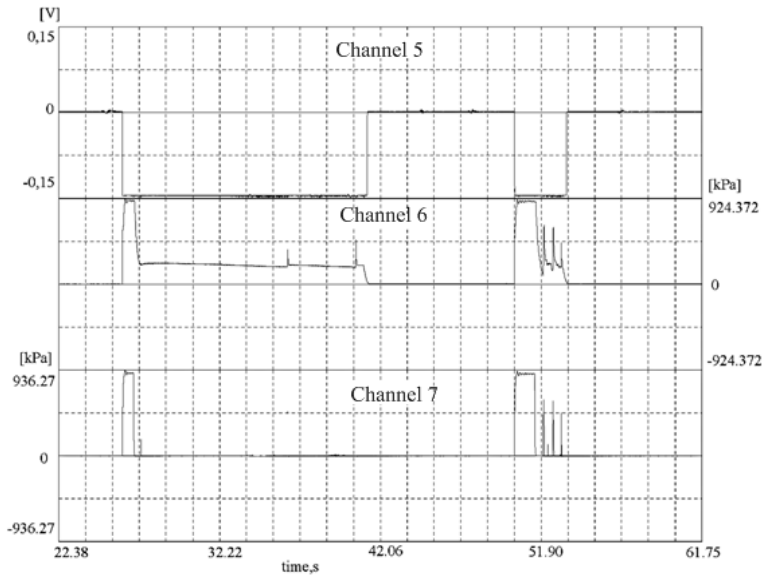

channel №5 - actuation of the microswitchof the clutch control mechanism; channel №6 - pressure in the power pneumatic chamberof the clutch control mechanism; channel №7 - pressure in the relay valve of the clutch control mechanism.

FIGURE VII. EXPERIMENTAL DATA OF THE PROCESSES CHANGES OCCURRING IN THE CLUTCH CONTROL MECHANISM IN THE VEHICLE STARTING SIMULATION MODE:

The results of the experimental studies have shown:

-The time of the clutch turning on / off realized by the developed mechanism of automatic clutch control complies with the requirements;

-The established dependence of the clutch fork rod from the position of the gas pedal provides a smooth start;

-We determined the value of the rational engine shaft speed for the vehicle starting. Within this value the movement with a clutch slip is carried out.

-The developed algorithms of the clutch control of the vehicle on the stand allowed us to reduce 4 times the dynamic loads at the vehicle starting, as well as reducethe time andthe clutch slipping, which significantly increases the longevity of the transmission parts.

\section{COMPARISON OF THEORETICAL AND EXPERIMENTAL DATA:}

The most obvious for comparison of theoretical and experimental research data is the area at the clutch fork rod position, ensuring a minimum clearance gap between the clutch plates when the gas pedal is released (see Figure 6,8). This theoretical position of the clutch fork rod is constant; it is equal to $17.25 \mathrm{~mm}$. Figure 8 shows the area of this dependence, which is part of the data in Figure 6. The graph (Figure 8) shows that the average difference between the theoretical and experimental data in the position of the clutch fork rod is $\Delta \mathrm{sr}=0.64 \mathrm{~mm}$ that makes $3.7 \%$ and satisfies the requirements for accuracy. 


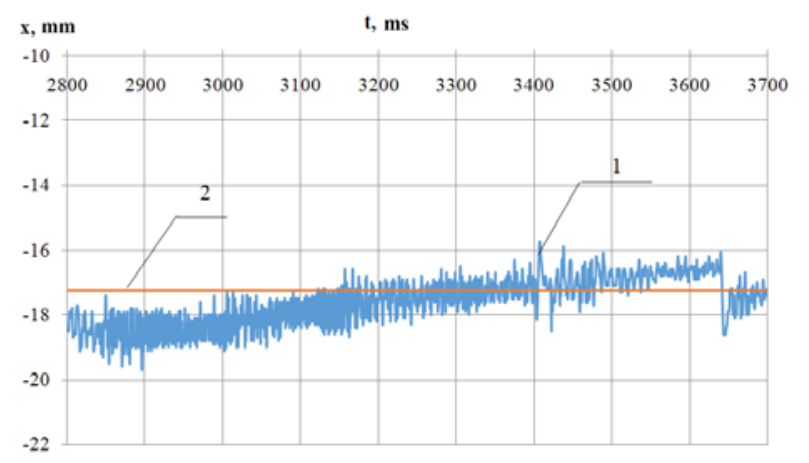

1 - the experimental value of the clutch fork shaft position;2- the theoretical value of the clutch fork shaft position.

\section{FIGURE VIII. COMPARISON OF THEORETICAL AND EXPERIMENTAL STUDIES:}

\section{CONCLUSION}

1) We considered the basic requirements applicable to the performance of the friction clutch control.

2) We developed a mechanism of the friction clutch automatic control, having the pneumatic drive for heavy trucks and trains that fully meet the requirements.

3) We installed the regression dependence of the displacement time of the clutch control acceleration mechanism piston from the basic parameters the pneumatic drive that are cross sectional area of the solenoid valve, the overall stiffness of the return spring and the piston diameter of the accelerator mechanism.

4) We carried out experimental studies of the efficiency of the automatic clutch control mechanism on a specialized stand. Thus we found out that:

-Turn on / off time of the clutch, realized by the developed mechanism of the automatic clutch control complies with the requirements;

-Embedded in the microprocessor control system, theoretical dependence of the stroke position of the clutch fork from the gas pedal position and the drive motor shaft speed ensures gentle start;

-We determined the value of rational engine speed for the vehicle start within which the movement with a slip clutch is carried out.

-The developed algorithms of the vehicle clutch control on the stand allowed us to reduce the dynamic loads when starting a vehicle 4 times as well as time and work of the clutch slip, which significantly increases the longevity of the transmission parts.

5) The discrepancy between these theoretical and experimental research for determination of the position of the clutch fork shaft does not exceed 3.7\%, which satisfies the accuracy requirements.

\section{ACKNOWLEDGEMENT}

This work was carried out at the NSTU named after R.E. Alekseev, with financial support from the government in the face of the Russian Ministry of Education under the Federal Program "Research and development on priority directions of the scientific-technological complex of Russia for 2014-2020", the unique identifier of the project: RFMEFI57414X0040.

\section{REFERENCES}

[1] A. P. Nedyalkov, The use of advanced technical solutions when creating mechanical step transmissions with automated control. / A. P. Nedyalkov, A. N. Blokhin // technomag.edu.ru: Science and Education: electronic science and technology publication. - 2011. - №2. URLhttp://technomag.edu.ru/doc/165381.html.

[2] A. N. Blokhin, Innovative transmissions "KOM-NAMI" with mechanical and automated control. / A.N. Blokhin, V. V. Mankovsky, A P. Nedyalkov // technomag.edu.ru: Science and Education: electronic science and technology publication. - 2011. - №9. URL http://technomag.edu.ru/doc/214551.html.

[3] A.P. Nedyalkov, Standard series of advanced unified multi-synchronized transmissions with automated control. / A. P. Nedyalkov, A. N. Blokhin, V. Y. Tumreev // Actual questions of Mechanical Engineering. Collection of scientific papers. Issue 1 - Minsk: AMI NAS of Belarus, 2012. - S. 216-221, ISSN2306-3084.

[4] A.N. Blokhin, The results of stand tests of sixteen speed transmission with automatic control. / A.N. Blokhin A.P. Nedyalkov, A.E. Kropp // technomag.edu.ru: Education \& Science: electronic science and technology publication. "- $2013 . \quad$ - №12 http://technomag.edu.ru/doc/671097.html.

[5] A.N. Blokhin, The results of computational and experimental studies of efficiency of the multistage mechanical transmission with automatic control / AN Blokhin AP Nedyalkov, AV Tumasov, AM Noskov // Actual questions of Mechanical Engineering. Collection of scientific papers. Issue 2 - Minsk: AMI NAS of Belarus, 2013. - S. 171-178, ISSN2306-308.

[6] A.N. Blokhin Process modeling of the transmission with multi-stage pneumatic drive clutch control- "Actual problems of Engineering" collection of scientific papers, MI NAS Berarus Minsk, 2014, pp. 139143.

[7] A. N. Blokhin, A. P. Nedyalkov Development and evaluation of performance electro-pneumatic clutch control mechanism of the vehicle - "Mechanics and Control Processes" volume 2 Materials of the XXXXIV All-Russian symposium on the 90th anniversary of academician V. P. Makeyev, - M .: Russian Academy of Sciences, 2014 pages 51-62.

[8] A. Blokhin, E. Denisenko, A. Kropp, A.Nedyalkov. The Study of the Synchronization Process in the Gearbox with Automatic Control// Applied Mechanics and Materials Vol. 763 (2015) pp 71-77.

[9] A.Blokhin, S.Dobryaev, A.Plekhov,V.Titov. Electromechanical Complex of Test Loading Stand of Multistage Transmissionswith Automatic Control // Applied Mechanics and Materials Vol. 763 (2015) pp 78-85. 